\title{
MODERN METHODS FOR AIR POLLUTION MONITORING
}

\author{
ARNALDO Liberti
}

\section{Laboratorio Inquinamento Atmosferico C.N.R., Istituto di Chimica Analitica, Università Città Universitaria, Rome, Italy}

\begin{abstract}
The monitoring of basic pollutants (sulphur oxides, nitrogen oxides, carbon monoxide, oxidants, hydrocarbons and particulate matter) to determine the air quality of a certain area is described.

The performance of air monitoring by static, mechanized or automatic devices in point sensors and by remote and long-path sensors is discussed and further possibilities forecast.
\end{abstract}

The evaluation of the status of the air is a challenging field for the analytical chemist, who is called upon to perform a task of a great importance for mankind: the development of methods and techniques to establish the quality of the basic material for life, the air.

Up to the end of the last century chemists' enquiries have been primarily concerned with the analysis of materials which occur naturally on the earth or which can be produced from these; emphasis was placed on research into a quantitative correlation of the materials of which the universe is made. The development of human society, the improved standard of living, the search for commodities required for a more comfortable life, oriented the creative achievements of chemists towards a variety of uses of natural resources; all, however, had an unpredictable impact and humanity is aware of the effects of the by-products of this activity upon the environment.

Historically man has assumed that the land, water and air around him would absorb his waste products. The atmosphere, like the ocean and the earth, was viewed as a receptacle of infinite capacity. The introduction in the atmosphere of pollutants of any kind, their diffusion and their interaction in the air affect the environment; today a new task has been given to the analytical chemist to which he may apply his best knowledge and science: the evaluation of environmental quality. The study of air, which was the object of early chemists, is again a problem of great importance and the analytical chemist has to develop specific analytical techniques and standard procedures to be able to determine the species which may pollute the atmosphere and to supply information upon the variety of reactions in the air menacing human health.

Two main problems are faced by the analytical chemist: what has to be monitored and how the monitoring has to be carried out.

It is well established that air quality is usually evaluated through a number 
of indices relative to the species listed in Table 1. These species are found in all areas of the industrialized world, the only differences between various places being the relative concentration of the species. It must, however, be emphasized that these indices do not fully represent the status of the air, as the indicated species are in dynamic equilibrium with the environment and according to meteorological, energetic and local conditions a variety of reactions may take place among them and with the components of the air.

Table 1. Urban pollutants

\begin{tabular}{ll}
\hline Sulphur oxides & $\mathrm{SO}_{x}\left(\mathrm{SO}_{2}, \mathrm{SO}_{3}\right)$ \\
Nitrogen oxides & $\mathrm{NO}_{x}\left(\mathrm{NO}, \mathrm{NO}_{2}\right)$ \\
Carbon monoxide & $\mathrm{CO}$ \\
Hydrocarbons & Alkanes, olefins \\
Oxidants & $\mathrm{O}_{3}$, peroxides, peroxy-acetylnitrate, etc. \\
Particulate matter & \\
\hline
\end{tabular}

The analytical chemist engaged in the study of the environment has the task of determining these indices and improving the present knowledge of air chemistry to obtain representative data.

To monitor an air pollutant it would be desirable to have an ideal sensor which would be able to yield an instantaneous and specific response for it which might be integrated and recorded with time. With few exceptions, however, such sensors are not available and in most cases the monitoring of a pollutant, sampled by either mechanized or automatic techniques, is carried out by bubbling air in a medium to bring into solution a certain species. The integrated sample collected over a long-term period (day, hours) or a short-term (minutes), as in automatic systems, is thus analysed and the concentration of the pollutants is evaluated by a variety of analytical procedures.

For the sake of classification these instruments are now designated as first-generation instruments. If the pollutant to be measured is a gas, it can be directly determined as such or through a gas phase reaction with a gaseous reagent partially specific. The detection of a pollutant can therefore be carried out through the formation of an excited species. The characteristic of this species is such that its emission spectrum has features which permit one to discriminate it from other compounds present or formed in the reaction.

Instruments of this type, defined as second-generation instruments, differ from their first-generation progenitors primarily in that they generate their signals as a result of a homogeneous gas phase reaction rather than by dissolving the substance to be analysed in a solution. It is quite obvious that as the circuitous route a gas has to follow to dissolve and react in solution is eliminated, these instruments offer definite advantages of sensitivity, specifity and simplicity of operation.

A third-generation instrument might also be conceived ${ }^{1}$. If a pollutant acts upon the chemoelectric properties of a transducer, a direct sensor can be obtained. Variations of such properties may yield an electrical analogue signal directly related to a certain pollutant concentration. 
The development of the instruments for air pollution monitoring is shown in Table 2.

Table 2. Instrumentation for air-pollutants analysis

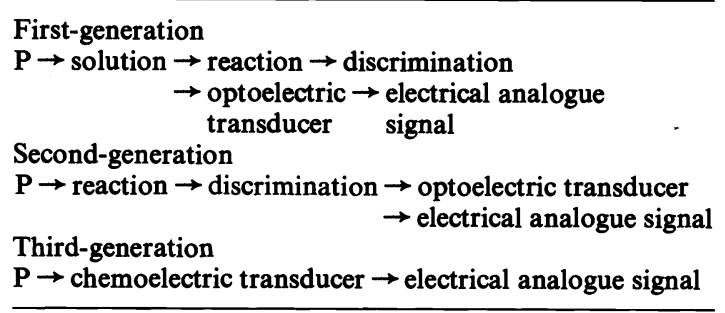

The trend to improve instrumentation aims to achieve the following features: (1) simplicity of concentration and operation; (2) reliability and reproducibility of operation over long time intervals; (3) adequate sensitivity to meet the requirements of specific applications; (4) specific response to pollutant or pollutants of interest.

Additional criteria apply to continuous air monitoring operations: (1) unattended operation; (2) real-time data output; (3) systems capable of monitoring two or more pollutants concurrently by the same measuring technique; (4) ability to monitor an increasingly wide range of pollutants; (5) capability for direct input to computers.

The monitoring of the urban pollutants according to the present development of analytical instrumentation is examined.

\section{SULPHUR OXIDES}

The determination of sulphur oxides, to which the greatest importance is always attributed for the evaluation of air quality, can be monitored by means of a variety of analytical techniques which are outlined in Table 3.

Table 3. Methods for monitoring sulphur oxides

\begin{tabular}{|c|c|c|}
\hline Acidimetry & $\mathrm{SO}_{2}+\mathrm{H}_{2} \mathrm{O}_{2} \rightarrow \mathrm{SO}_{4}^{2-}+2 \mathrm{H}^{+}$ & $\begin{array}{l}\text { manual-nocific } \\
\text { mon- }\end{array}$ \\
\hline Conductimetry & $\mathrm{H}_{3} \mathrm{O}^{+}, \mathrm{SO}_{4}^{2-}$ (conductance) & $\begin{array}{l}\text { continuous non- } \\
\text { specific }\end{array}$ \\
\hline Colorimetry & $\begin{array}{l}\mathrm{H}_{2} \mathrm{O}+\mathrm{SO}_{2}+\mathrm{HgCl}_{4}^{2-} \rightarrow\left[\mathrm{HgCl}_{2} \mathrm{SO}_{3}\right]^{2-} \\
+2 \mathrm{H}^{+}+2 \mathrm{Cl}^{-}+\mathrm{HCOH}+p \text {-rosaniline }\end{array}$ & $\begin{array}{l}\text { manual-continuous } \\
\text { specific-reference } \\
\text { method }\end{array}$ \\
\hline $\begin{array}{l}\text { Potentiometry and } \\
\text { coulometry }\end{array}$ & $\mathrm{SO}_{2}+\mathrm{Br}_{2}+2 \mathrm{H}_{2} \mathrm{O} \rightarrow \mathrm{SO}_{4}^{2-}+4 \mathrm{H}^{+}+2 \mathrm{Br}^{-}$ & $\begin{array}{l}\text { non-specific } \\
\text { automatic }\end{array}$ \\
\hline Flame photometry & $\mathrm{S}_{2}^{*} \rightarrow \mathrm{S}_{2}+h v$ & specific \\
\hline
\end{tabular}

The selection of an analytical procedure depends upon the aim, which has to be reached from the monitoring and the cash investment allotted. It can be realized with very simple equipment by making use of manual operations 
and with a quite elaborate instrumentation for continuous and automatic monitoring.

All instruments with the exception of the flame photometric detector (FPD) system ${ }^{2}$ belong to the first-generation instruments. Though at the present the colorimetric procedure (West and Gaeke method) ${ }^{3}$ is taken as a reference method, the advantages of the FDP system are evident. When a sample of air is burned in a hydrogen-rich flame, all volatile sulphur compounds are converted to diatomic sulphur, which is raised to an excited state as it rises in the flame. This excited species is sufficiently long-lived to reach a region above the flame, where it returns to the ground state condition. The transition from an excited state $S_{2}^{*}$ to the ground state releases a light energy whose spectrum is shown in Figure 1. For analytical applications the peak emission band at $394 \mathrm{~nm}$ can be resolved by use of interference filters. Because two sulphur atoms are required to produce one excited molecule, the light intensity emitted is proportional to the sulphur concentration squared.

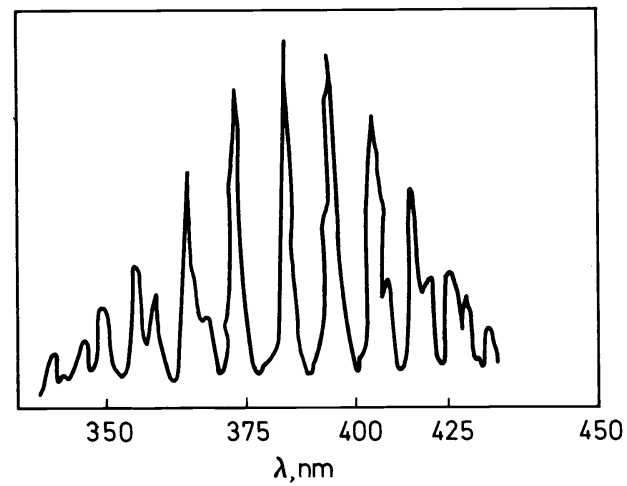

Figure 1. Chemiluminescence spectrum for sulphur $\left(\mathrm{S}_{2}\right)$

Emission from the flame itself produces a background signal that limits sensitivity. This background can be reduced by shielding the flame and by reducing the flame temperature. The sensitivity of PFD is $0.2 \mathrm{ng} \mathrm{S}$ and the response is linear up to $100 \mathrm{ng} \mathrm{S}$.

In the detector a photomultiplier converts the light energy into an electrical signal. The main advantages of this device are its specificity, for the absence of intermediate reaction, a real-time data output being almost instantaneous in its response to $\mathrm{SO}_{2}$ concentration, and the wide range of measurable concentration. The FPD records, however, all sulphur compounds and though this term is practically synonymous with sulphur dioxide, interference from other sulphur pollutants can be accounted for. Discrimination among various sulphur compounds can be achieved by inserting a short gas chromatographic column to obtain their fractionation ${ }^{4}$. This aim is obtained by using a graphitized carbon black column coated with GEXE 60 and phosphoric acid:hydrogen sulphide, sulphur dioxide, mercaptans and 
disulphides which are mainly responsible for an additional toxic effect, the urban odour, can be determined as well ${ }^{10}$.

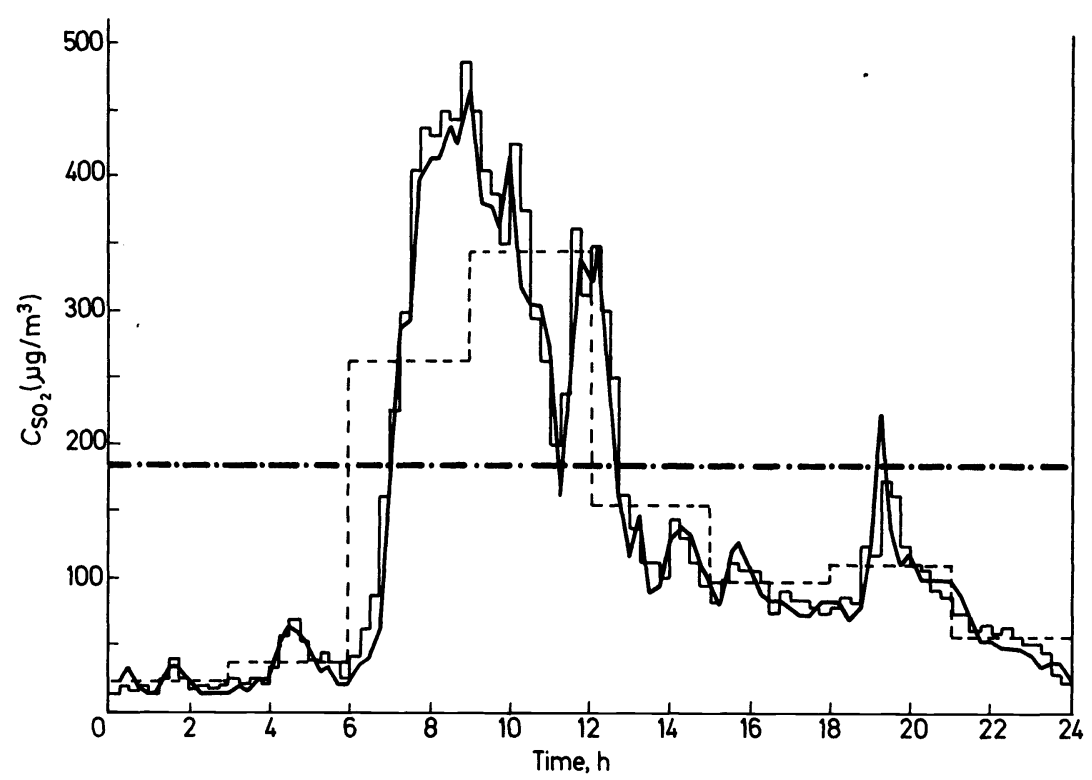

Figure 2. Determination of atmospheric sulphur dioxide by various procedures: $-\cdot-$ alkalimetric titration (24 h sampling); _ _ - West and Gaeke colorimetric method ( $3 \mathrm{~h})$; coulometry $(15 \mathrm{~min})$; - flame photometry $(3 \mathrm{~min})$

Figure 2 compares the measurements of the sulphur dioxide manually by acidimetry on a day sampling, by a standard colorimetric method after $3 \mathrm{~h}$ sampling, by automatic coulometry and by FPD. The coulometric system employed gives an integral response over $15 \mathrm{~min}$, whereas the sampling rate for FDP, which operates discontinuously, was 3 min.

Comparison of various procedures indicates the various possibilities which can be realized by various analytical techniques.

\section{NITROGEN OXIDES}

The methods for determining nitrogen oxides are summarized in Table 4.

The Saltzman method ${ }^{6}$ which employs sulphanilic acid for diazotization and $N$-naphthyl ethylenediamine dihydrochloride for coupling has been used so far quite extensively in manual and automatic procedure. Though this method is taken as a reference, criticism has been raised against it for the non stoichiometric response and for the various interferences. The measurement of nitrogen oxides can be now carried out by means of a secondgeneration instrument through a chemiluminescent homogeneous gas phase reaction $^{5}$. A phenomenon once classified as a laboratory curiosity, the chemiluminescent reaction of nitrogen oxide and ozone, provides the basis 


\section{ARNALDO LIBERTI}

Table 4. Methods for monitoring nitrogen oxides

\begin{tabular}{|c|c|c|}
\hline \multicolumn{3}{|l|}{ Colorimetry } \\
\hline Griess-Saltzman & $\begin{array}{l}\mathrm{NO}_{2}+\text { sulphanilic acid }+\mathrm{N}- \\
\text { (1-naphthyl)-ethỷlenediamine } \\
\rightarrow \text { azo dye }\end{array}$ & $\begin{array}{l}\text { Manual and automatic- } \\
\text { specific for } \mathrm{NO}_{2}(\mathrm{NO} \text { is } \\
\text { measured after oxidation to } \\
\left.\mathrm{NO}_{2}\right)\end{array}$ \\
\hline Coulometry & $\begin{array}{l}\mathrm{NO}_{2}+2 \mathrm{H}^{+}+2 \mathrm{Br}^{-} \\
\quad \rightarrow \mathrm{NO}+\mathrm{H}_{2} \mathrm{O}+\mathrm{Br}_{2}\end{array}$ & Non-specific-automatic \\
\hline Chemiluminescence & $\begin{aligned} \mathrm{NO}+\mathrm{O}_{3} \rightarrow \mathrm{NO}_{2}^{*}+\mathrm{O}_{2} & \\
& \mathrm{NO}_{2}+h v(0.6-2.8 \mu \mathrm{m})\end{aligned}$ & $\begin{array}{l}\text { Specific for } \mathrm{NO} \text { - continuous } \\
\left(\mathrm{NO}_{2} \text { is measured after }\right. \\
\text { catalytic conversion to NO) }\end{array}$ \\
\hline Fluorescence & $\begin{array}{l}\text { Laser excitation of } \mathrm{NO}_{2} \text { at } 441.6 \\
\text { and } 448 \mathrm{~nm}\end{array}$ & $\begin{array}{l}\text { Specific for } \mathrm{NO}_{2} \text { (NO is } \\
\text { measured after oxidation) }\end{array}$ \\
\hline
\end{tabular}

for the determination of these compounds. When ozone is added to a gas stream containing nitrogen oxide, the following reactions take place:

$$
\begin{aligned}
& \mathrm{NO}+\mathrm{O}_{3} \longrightarrow \mathrm{NO}_{2}+\mathrm{O}_{2} \\
& \longrightarrow \mathrm{NO}_{2}^{*}+\mathrm{O}_{2} \\
& \mathrm{NO}_{2}^{*} \longrightarrow \mathrm{NO}_{2}+h v(>6000 \AA) \\
& \mathrm{NO}_{2}^{*}+\mathrm{M} \longrightarrow \mathrm{NO}_{2}+\mathrm{M}(\mathrm{M}=\text { gas solvent })
\end{aligned}
$$

Light emission results when electronically excited $\mathrm{NO}_{2}^{*}$ molecules revert to their ground state. To measure NO concentrations, the gas sample is blended with $\mathrm{O}_{3}$ in a flow reactor. The resulting chemiluminescence is monitored through an optical filter by a high-sensitivity photomultiplier positioned at one end of the reactor. The apparatus is shown schematically in Figure 3.

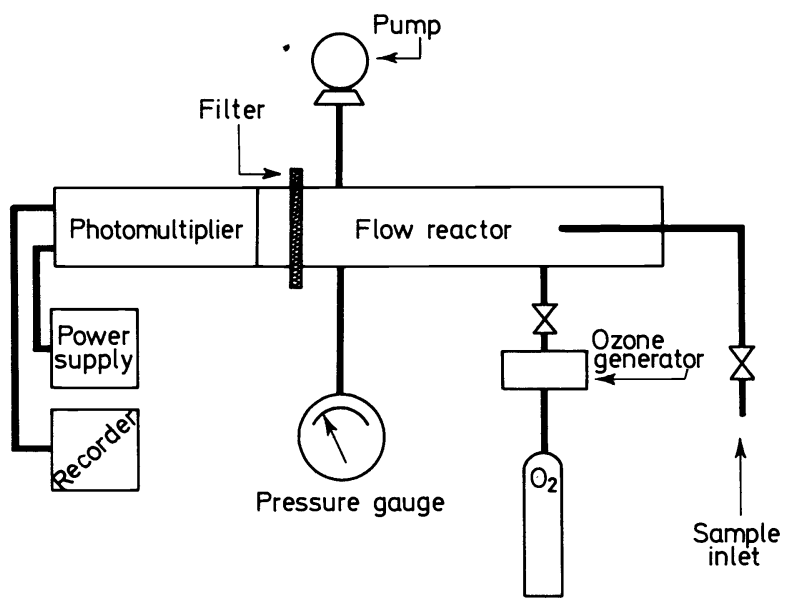

Figure 3. A chemiluminescence analyser for nitrogen oxides 
Chemiluminescence (CL) emission is a continuum from 0.6 to $3.0 \mu \mathrm{m}$. In the presence of excess $\mathrm{O}_{3}, \mathrm{CL}$ intensity is proportional to NO concentration. Greatest sensitivity is obtained at reduced pressure because of quenching effects at higher pressures. Nevertheless ambient NO concentrations can be measured also at atmospheric pressure. At reduced pressure with a cooled photomultiplier tube this method can detect 0.001 p.p.m. NO. Response is linear up to 10000 p.p.m. with a linear dynamic range of $10^{7}$. Because ozone reacts with other atmospheric contaminants to generate $\mathrm{CL}$, a cut-off filter absorbing wavelengths shorter than $600 \mathrm{~nm}$ is included in $\mathrm{NO}$ monitors. Total oxides of nitrogen $\left(\mathrm{NO}+\mathrm{NO}_{2}\right)$ can also be determined by reducing $\mathrm{NO}_{2}$ to $\mathrm{NO}$ with carbon before reacting with ozone.

A real time measurement of $\mathrm{NO}_{2}$ can be realized by means of molecular fluorescence by using laser excitation at $441.6(\mathrm{He}-\mathrm{Cd}$ laser) or at $488 \mathrm{~nm}$ (argon ion laser) and photon counting ${ }^{7}$. The interesting features of this method are the high sensitivity, which is about one part per billion, and the rapidity of the response time, which conduces to 'instantaneous' $\mathrm{NO}_{2}$ concent:- ion. By bubbling the incoming air through an oxidizing solution $\mathrm{NO}$ is converted to $\mathrm{NO}_{2}$ and determined.

\section{OXIDANTS}

Ozone and oxidants can be monitored by the procedures outlined in Table 5. The most widely used is the neutral buffered KI method, which is accepted as the reference method for ozone determination and also for calibration purposes.

Table 5. Methods for monitoring oxidants

\begin{tabular}{|c|c|c|}
\hline $\begin{array}{l}\text { Colorimetry: } \\
\text { Neutral KI method . }\end{array}$ & $\begin{array}{l}\underset{\mathrm{KI}}{\rightarrow}+\mathrm{O}_{3}+\mathrm{H}_{2} \mathrm{O} \\
\quad \mathrm{O}_{2}+\mathrm{KOH}+\mathrm{KI}_{3}\end{array}$ & $\begin{array}{l}\text { manual and automatic- } \\
\text { total oxidants- } \\
\text { reference method }\end{array}$ \\
\hline $\begin{array}{l}\text { Electrochemistry: } \\
\text { Galvanic analyser } \\
\text { Amperometric- } \\
\text { coulometric analyser }\end{array}$ & $\mathrm{O}_{3}+2 \mathrm{Br}^{-} \rightarrow \mathrm{O}_{2}+\mathrm{O}_{2}^{2-}+\mathrm{Br}_{2}$ & $\begin{array}{l}\text { specific for } \mathrm{O}_{3}- \\
\text { continuous } \\
\text { non-specific }\end{array}$ \\
\hline Chemiluminescence & $\begin{array}{c}\mathrm{O}_{3}+\mathrm{C}_{2} \mathrm{H}_{4} \rightarrow \mathrm{HCHO}+\mathrm{HCOOH} \\
+h v(4300 \AA)\end{array}$ & specific for $\mathrm{O}_{3}$-automatic \\
\hline Ultra-violet photometry & Absorption at $\lambda=2537 \AA$ & specific for $\mathrm{O}_{3}-$ automatic \\
\hline
\end{tabular}

A variety of electrochemical procedures have been also developed, such as the amperometric-coulometric and the galvanic detection methods ${ }^{8}$. In the former a platinum wire helix electrode is wetted by an iodine solution, circulated by a pump. The iodine set free is continuously reduced by an applied cathodic potential and the current flowing between the cathode and the wire loop anode is assumed to be a linear function of the ozone concentration. A scheme of the latter is shown in Figure 4. Air is divided into two equal streams, bubbling into a recirculating neutral buffered 
electrolyte (bromide with traces of iodide). By selective removal of reducing agents in both sections and ozone in only one section, the differential galvanic current required to reduce galvanically the halogen set free at a platinum electrode is measured.

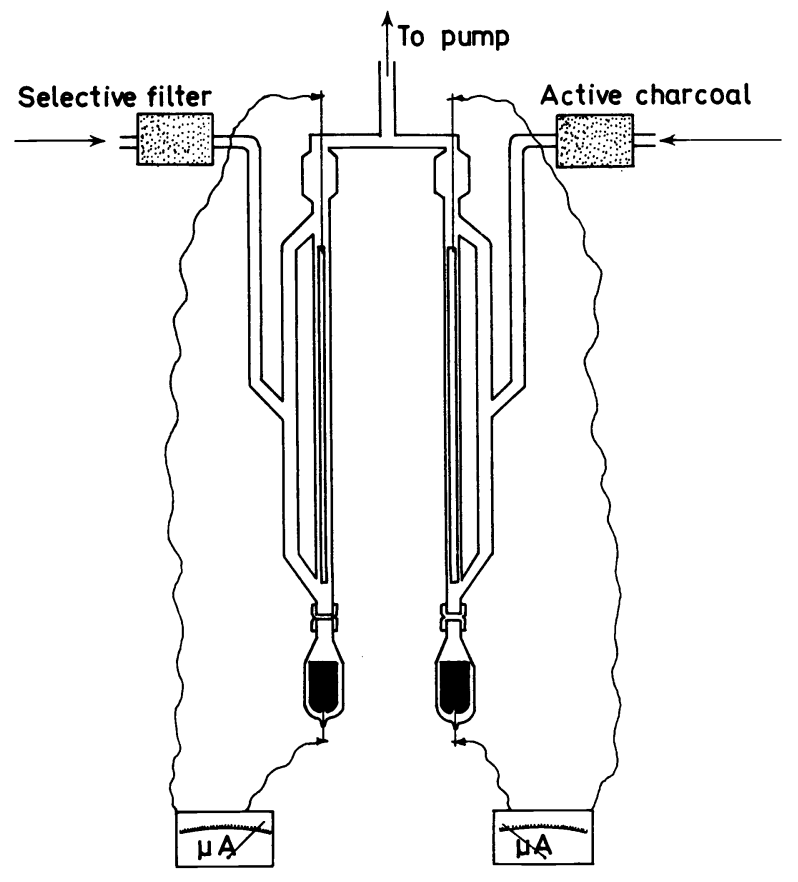

Figure 4. Galvanic analyser for ozone

Besides instruments of the first generation it is worth mentioning the development of a second-generation instrument to monitor ambient levels of ozone. A set-up similar to the one described for nitrogen oxides can be used by reversing the roles of $\mathrm{O}_{3}$ and $\mathrm{NO}$ or by replacing nitrogen oxide with an olefin. Alternatively, a highly sensitive and specific procedure can be realized by making use of the chemiluminescent reaction between ozone and rhodamine B. A disc coated with this dye and gallic acid in the presence of ozone yields a luminescence detected by a phototube and the current generated is directly related to the mass of ozone per unit time flowing over the dye.

The determination of oxidants and their precursors in the atmosphere, which are believed to be the nitrogen oxides and certain organic compounds, namely unsaturated hydrocarbons, is becoming of increasing importance as the concentration of oxidants can be taken as a measurement of photochemical smog, i.e. the smog which occurs under oxidizing condition. This type of pollution, well recognized in certain areas, is a matter of great concern and might have a definite effect upon the air quality. 


\section{CARBON MONOXIDE}

Methods used to monitor carbon monoxide are summarized in Table 6.

Table 6. Methods for monitoring carbon monoxide

\section{Titrimetry}

Iodine pentoxide

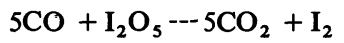

Manual-specific

Colorimetry

Silver sol method

$\mathrm{Ag}^{+}$(complex) $\rightarrow \mathrm{Ag}$

Indicating gel tubes

Molybdate reduction

Non-dispersive infra-red analysis

Catalytic analysis

IR at $4.7 \mu \mathrm{m}$

Manual-non-specific

Manual-non-specific

Specific-automatic

Oxidation of $\mathrm{CO}$ with hopcalite Non-specific-manual and
continuous

Electrolysis

$\mathrm{CO}+\mathrm{H}_{2} \mathrm{O}--\mathrm{CO}_{2}+2 \mathrm{H}^{+}+2 \mathrm{e}$ Specific-continuous

Gas chromatography

Reduction to $\mathrm{CH}_{4}$, detection by f.i.d. Non-specific - automatic

The monitoring of carbon monoxide is usually carried out by non-dispersive infra-red spectroscopy and by the hopcalite method. Recently an interesting electrochemical procedure has been developed ${ }^{9}$. The operative principle is the electrooxidation of carbon monoxide in a sulphuric acid solution to carbon dioxide at a catalytically active platinum electrode, according to the equation

$$
\mathrm{CO}+\mathrm{H}_{2} \mathrm{O} \longrightarrow \mathrm{CO}_{2}+2 \mathrm{H}^{+}+2 \mathrm{e}
$$

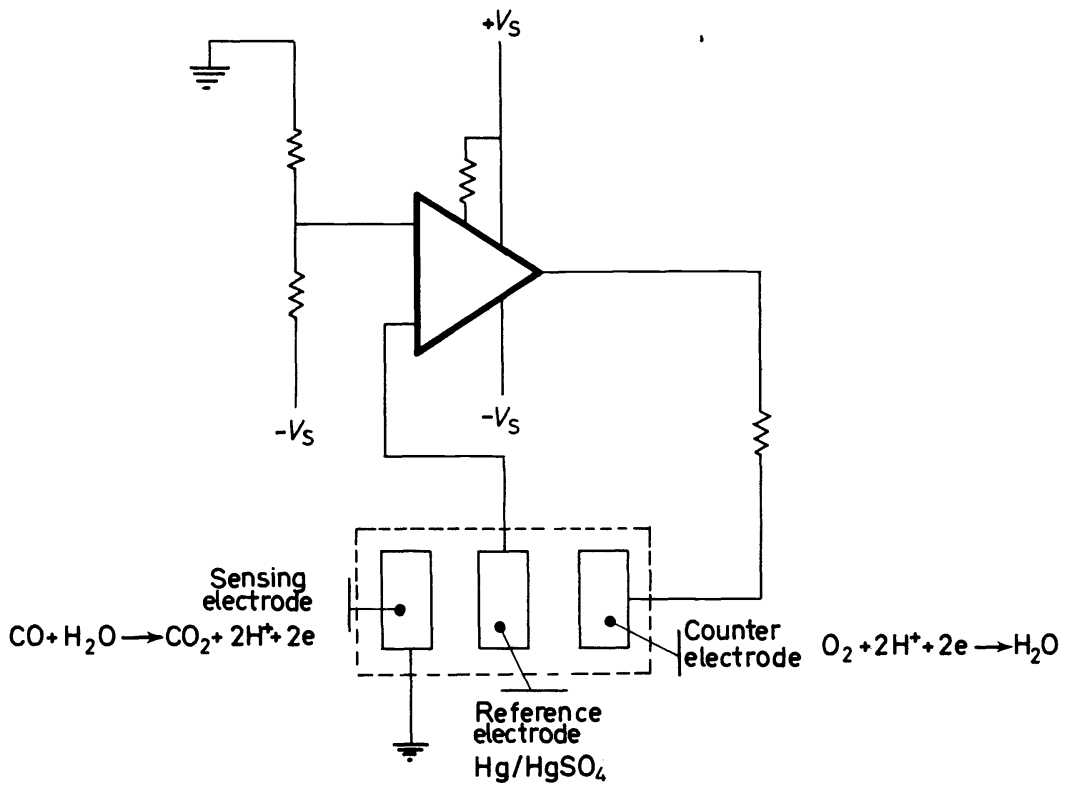

Figure 5. Electrochemical sensor for carbon monoxide 
The anode is a potential-controlled electrode maintained within the range $0.9-1.5 \mathrm{~V}$ versus NHE by means of a mercury/mercury sulphate reference electrode. The process of oxidation of carbon monoxide occurs uniquely at the sensing electrode while no other reaction takes place there at an appreciable rate. At the cathode, oxygen is reduced to water (Figure 5).

During the operation the air sample is pumped at constant flow rate over the anode, where the carbon monoxide diffuses to the electrocatalytic surface, where it is electrooxidized. The diffusion-limited current, which flows between the sensing and counter electrodes, is proportional to the carbon monoxide concentration in the gas sample. The carbon dioxide formed by the electrochemical reaction is removed continuously from the cell at the same rate as that at which it is formed. The electrochemical sensor is quite selective, has a fast response and is unaffected by air humidity, which is a limitation in I.R. analysers.

\section{HYDROCARBONS}

The determination of hydrocarbons is carried out by delivering semicontinuously air to a hydrogen flame ionization detector; its response is proportional to the total hydrocarbon content. As methane is a natural air component which is present in fairly high concentrations (about 1 p.p.m.), its concentration has to be determined and the value of total hydrocarbons corrected for the methane content. This is achieved by introducing an air sample into a stripper column through which there is a continuous flow of hydrogen carrier gas. Hydrocarbons heavier than methane are retained and further backflushed, whereas methane and carbon monoxide are passed to a gas chromatographic column where they are separated, the methane being eluted first. Alternatively, the determination can be carried out by means of a dual detector system ${ }^{10}$. One flame ionization detector, directly fed with the ambient air, measures the total amount of hydrocarbons, and the other, set at the end of a column packed with Porapak Q, measures only methane.

Besides the continuous measurement of total hydrocarbons, it is of major importance to obtain information about various classes of hydrocarbons and also organic contaminants, which have significantly different reactivities and may have a definite impact upon the air quality. In order to achieve this aim, it is required to trap the organic components of a certain volume of air and to analyse the sample. One of the most efficient systems is the device described by Bruner and co-workers ${ }^{11}$, which consists of a trap, filled with suitable material (graphitized Carbon Black) set in a Dewar flask with liquid nitrogen. After sampling, the trap is connected with a gas chromatographic column and heated up. The desorbed compounds are directly injected into a chromatographic column where volatile hydrocarbons such as alcanes and olefins with carbon number $\mathrm{C}_{2}-\mathrm{C}_{6}$, usually found in an urban area, are separated. For the determination of heavier compounds a solvent extraction with carbon disulphide is required and with a suitable column a full 'spectrum' of the organics present in the air can be obtained. 


\section{PARTICULATE MATTER}

The term 'particulate matter' is used to define any solid or liquid matter dispersed in the atmosphere. Particulate matter originates from a variety of sources and for its complex composition several parameters should be taken into account to evaluate the impact upon human health and materials. They may be summarized as follows: (a) total masss loading expressed as mass of particulate in a given volume of air; (b) relative mass resulting from particles in a given size range to evaluate the relative contribution to respirable aerosols; (c) chemical composition to evaluate the concentration of definite harmful chemicals such as $\mathrm{H}_{2} \mathrm{SO}_{4}$, silica, $\mathrm{Hg}, \mathrm{Be}$, asbestos, polycyclic hydrocarbons, etc.; (d) optical parameters which should be investigated to evaluate effects such as visibility reduction and variation in the total solar energy budget.

Mass measurements can be done by drawing air through suitable filter media which are weighed up before and after sampling. This procedure suffers definite limitations due to several factors which should be carefully controlled (sampling rate, linear flow rate and filter); it is, however, the only direct way for mass measurement and is the most suitable for this purpose.

An automatic dust monitor can be also realized by making use of a ' $\beta$ rays gauge'. A known volume of air is drawn by a constant flowrate pump and filtered over the fibre tape, which moves intermittently between a radiation counting gate and an air sampling gate. The mass of the filtered matter is determined through absorption of low-energy beta-radiation by ratioing the impulse rates given by irradiation of the dusted and undusted filter. The radiation absorbed is proportional only to the mass of filtered matter and is independent of its density, chemical composition and physical or optical properties.

Other methods are based on indirect measurements of mass through physical properties of particulate matter. For example, for urban pollution the so-called 'soiling index' is quite often used. The air drawn through a filter paper leaves on it a dark stain. The darkness of the stain is interpreted as a surface concentration of particulate matter, and by means of a calibration curve obtained with a standard smoke the volume concentration is calculated.

These procedures supply only the concentration of particulate matter; both the inorganic and the organic fractions have to be analysed for the determination of those species which have a specific impact on human health ${ }^{12}$.

\section{FLUORIDE}

Among pollutants arising from industrial sources it is worth mentioning the development of automatic continuous analysers to monitor fluorides. Hydrogen fluoride and soluble fluoride particulates can be determined by the classical colorimetric procedure based on the bleaching of alizarin complexan, which can be carried out also in a continuous way and by a recently developed potentiometric procedure ${ }^{13}$ making use of a fluoride electrode as sensing device. Figure 6 shows the scheme of this analyser. The 


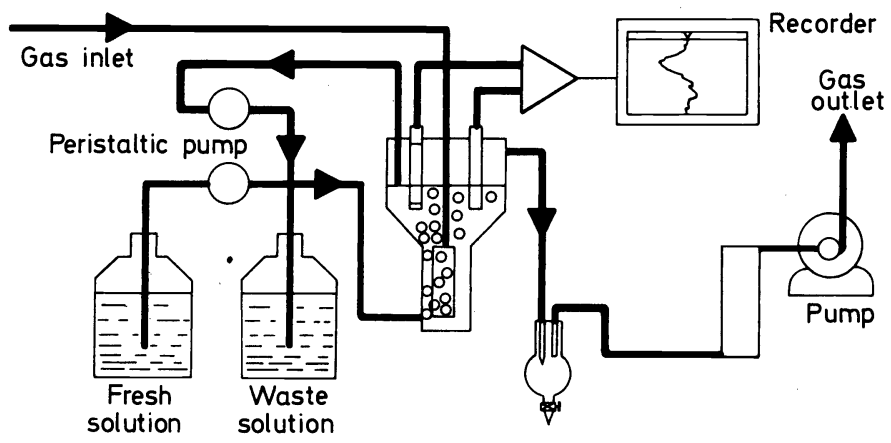

Figure 6. Potentiometric fluoride analyser using as sensor an ion-sensitive fluoriut electrode

gas reacts with an adsorbing solution made of a citrate buffer, which ensures constant $\mathrm{pH}$ and ionic strength. From the e.m.f. supplied by a cell consisting of a fluoride-ion electrode and a calomel electrode, the free fluoride concentration of the solution is obtained. The absorbing solution is renewed continuously at a predeterminate rate in order to have the sensor, whose response is a logarithmic function of fluoride concentration, operate in the range where it exhibits a higher sensitivity. As both the flow of sampled gas and the flow of absorbing solution are kept constant, the measured tension is linearly correlated to the content of fluoride in the sampled gas. The measurement is carried out over a definite period of time selected in accordance with the flow of the sampled gas and the absorbing solution, and the measured fluoride is thus the average value over the selected sampling time.

\section{PERFORMANCE OF AIR MONITORING}

The examination of modern methods used for air monitoring permits one to answer the second question: how air monitoring has to be performed.

The variety of analytical methods offers a wide selection of procedures, which can be carried out by means of static, mechanized or automatic devices. The choice will depend upon the use of the monitoring data and the aim which has to be reached.

Static devices, such as the ones employed to measure the amount of settleable particulates (dust fall) or the rate of sulphation, are used for mapping, for definition of special problem areas and for general survey. Mechanized bubbler devices are used to collect sulphur dioxide, nitrogen dioxide, mercury, and other gases and vapours. These samplers, although typically designed for collecting $24 \mathrm{~h}$ integrated samples, can be modified to collect 1 or $2 \mathrm{~h}$ samples in sequence, and thus allow definition of diurnal variations.

In automatic sampler-analysers, collection and analysis are combined in a single device. These automatic instruments produce continuous analysis, with the output in a machine-readable format or in a form suitable for telemetry to a central data-acquisition facility. 


\section{MEASUREMENT APPROACHES FOR STATIONARY SOURCES}

The approach of the various instruments described to monitor a pollutant either by laboratory analysis or by analysers is the same. These instruments can be called 'point' sensors as they measure the concentration of the given pollutant at a single point. Another approach for monitoring is the 'remote sensing. This term indicates the use of instruments which can provide the average concentration of a pollutant in a certain area either by looking at the emissions as they exit at the mouth of a stack or by sampling an optical volume at a point within the plume and conducting a spatially integrated measurement across the diameter of the plume. Remote sensing can be performed also by means of a 'long-path sensor'; this term indicates any device which permits one to measure extended or diffuse sources, such as oil refineries and chemical complexes between two points.
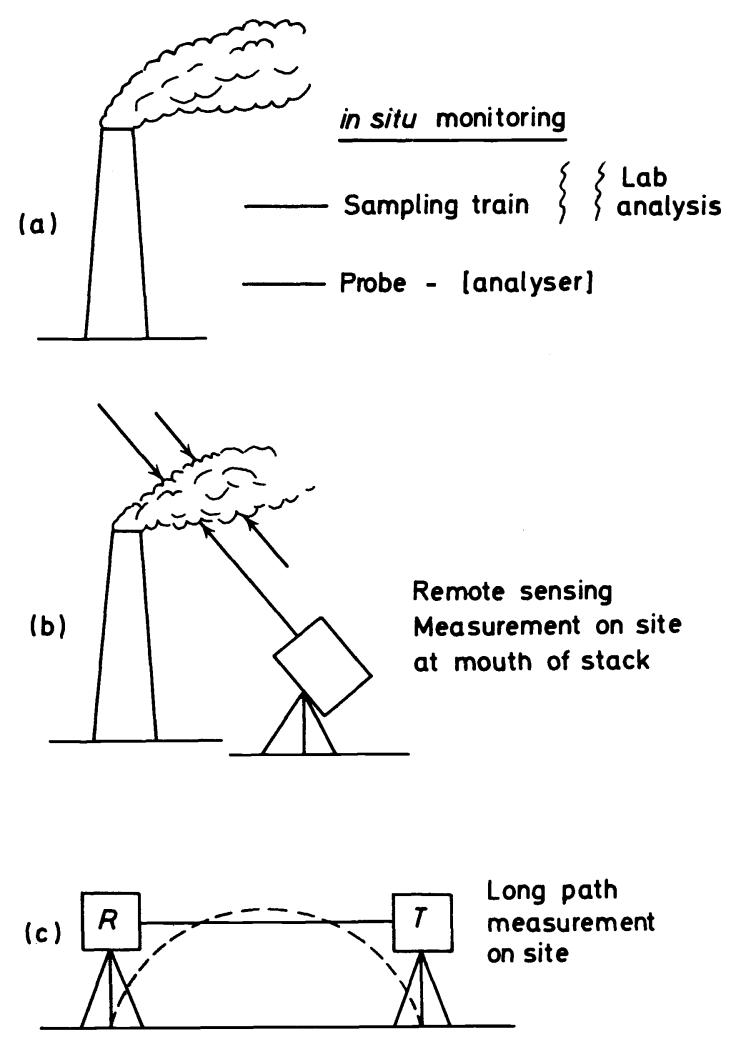

Figure 7. Different approaches for monitoring pollutants from stationary sources

The various approaches for monitoring pollutants from stationary sources are outlined in Figure 7. 


\section{ARNALDO LIBERTI}

Remote and long-path sensors should greatly simplify the monitoring of a certain area and a variety of spectroscopic techniques have been applied for these instruments. The one most highly developed is the correlation spectrometer, where a replica of an absorption or emission spectrum is compared with a dispersed light beam which has passed through the target gas $^{14}$. The basic principle is the following. Reflected or scattered radiation from a distant source is collected in a telescope and dispersed through a spectrometer of the grating or prism type. The spectrum of the radiation is projected into an optical mask which carries a photographic replica of the spectrum of the gas being detected. An oscillating refractor plate or some other suitable means is used to vibrate the spectrum of the gas which has to be analysed across the mask and the output of the photodetector behind the mask is sensed for the presence of a beat signal. If there is a correlation between the incoming radiation and the mask, there will be a beat signal as the dispersed radiation vibrates periodically in and out, matching with the mask. An automatic gain control keeps the average d.c. output of the photo-
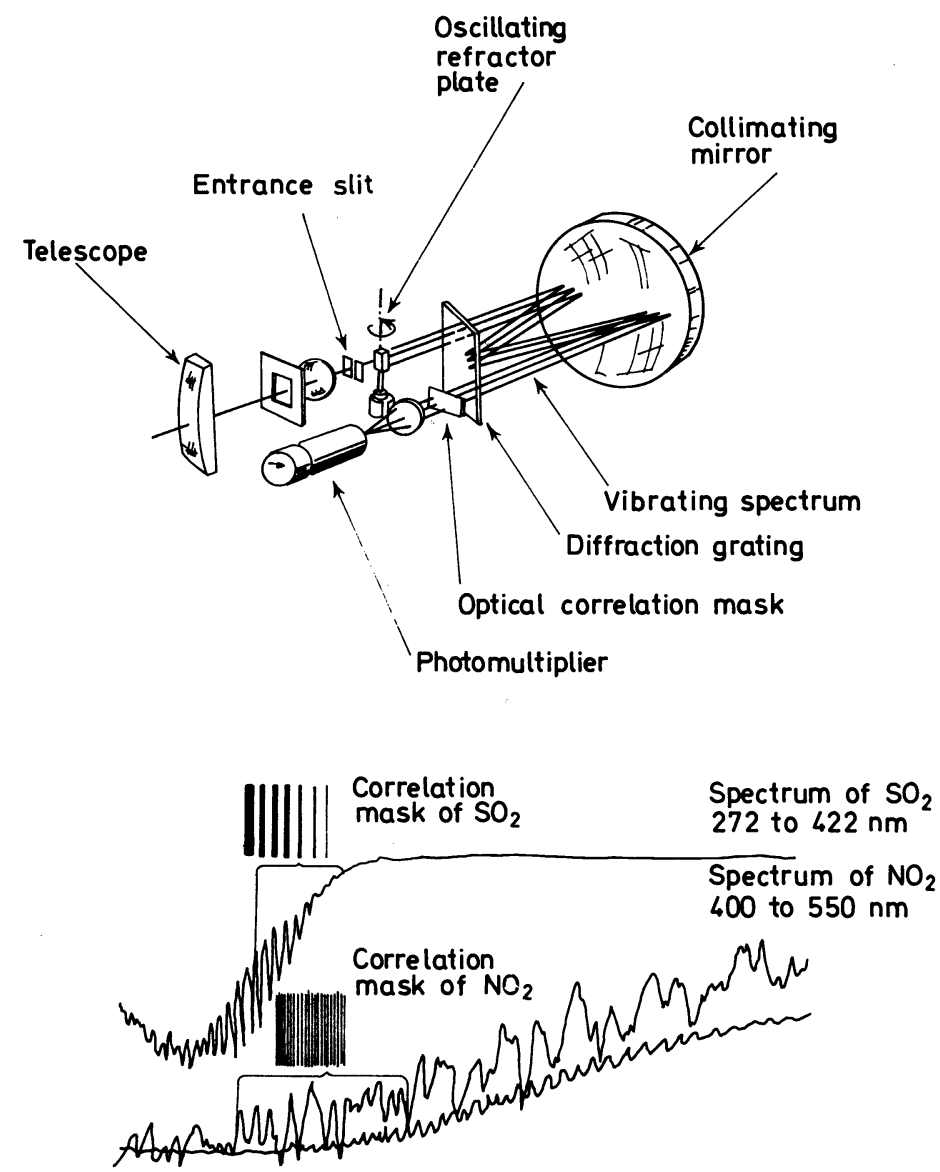

Figure 8. Scheme of a correlation spectrometer with spectra of $\mathrm{SO}_{2}$ and $\mathrm{NO}_{2}$ 
detector constant so that the amplitude of the beat signal becomes a quantitative measurement of certain pollutants; the lack of a beat signal indicates the absence of a certain species (Figure 8).

The principle of the instrument is based on the Lambert-Beer law of absorption $\left(I=I_{0} \mathrm{e}^{-a c}\right)$. The correlation spectrometer can use as an energy source natural daylight or artificial light; it can be set on aircraft to obtain profiles of pollutants when flights are made across pollution sources such as power stations and large industrial establishments.

Long-path monitoring can be realized also by means of a two-beam differential infra-red spectrometer using a tunable $\mathrm{CO}_{2}$ laser ${ }^{15}$. The use of two beams - one tuned to a prominent line of the absorption spectrum of the desired gas, the other to an adjacent non-absorbing region-eliminates the effect of atmospheric optical turbulence and scintillation, interference from molecules and other scattering. An urban air pollution monitoring centre may be envisaged as a system of lasers emitting radial beams from a central location. Corner reflectors will return the radiation to receivers which determine the differential absorption over the two-way path on both wavelength channels.

Another technique frequently proposed for long-path measurements involves Raman scattering of a laser beam ${ }^{16}$. Raman spectra result from inelastic collision of monochromatic photons with molecular species during scattering, resulting in bands or lines of shifted wavelength. This wavelength shift is a function of the molecular vibrational modes and permits unique identification of the molecule.

A variety of spectroscopic techniques has been developed, and the actual status of instrument development for gases by remote and long-path sensors is summarized in Table 7. Some instruments such as the correlation spectrometer are commercially available and others are under development.

Table 7. Status of instrument development for gases

\begin{tabular}{|c|c|}
\hline Remote sensor & Long-path sensor \\
\hline \multicolumn{2}{|c|}{$\begin{array}{l}\text { UV correlation spectrometer }\left(\mathrm{NO}_{2}-\mathrm{SO}_{2}\right) \\
\text { Raman scattering (multi-gas) }\end{array}$} \\
\hline $\begin{array}{l}\text { IR Emission spectroscopy } \\
\text { Fluorescence and resonance } \\
\text { Raman scattering (NO) } \\
\text { IR laser } \quad\left(\mathrm{SO}_{2}\right)\end{array}$ & $\begin{array}{l}\text { IR absorption spectroscopy } \\
\text { Non-dispersive IR (CO) }\end{array}$ \\
\hline
\end{tabular}

The variety of the analytical techniques developed indicates the effort which has been made to meet the challenges of newly recognized pollutants, to monitor more efficiently those already known and to obtain a better understanding of the variations of the environment.

The large number of analytical methods and instruments is a demonstration of the great amount of research made by analytical chemists to cope with one of the main problems of modern society. The complexity of air chemistry still requires, however, a continuous effort to develop and improve monitoring methods. 


\section{ARNALDO LIBERTI}

\section{REFERENCES}

1 A. E. O'Keeffe, IEEE Trans. Geosci. Electron. 8, 145 (1970).

2 S. S. Brody and J. E. Cheney, J. Gas Chromatogr. 4, 42 (1966).

3 P. W. West and G. C. Gaeke, Anal Chem. 28, 1816 (1956).

${ }^{4}$ F. Bruner, A. Liberti, M. Possanzini and I. Allegrini, Anal. Chem. 44, 2070 (1972).

5 A. Fontijn, A. Sabaldel and A. R. J. Conco, Anal. Chem. 45, 575 (1970).

6 B. E. Saltzman, Anal. Chem. 26, 1949 (1954).

7 J. A. Gelbwach, M. Birnbaum, A. W. Tucker and C. L. Fincher, Opto-electronics, 4, 155 (1972).

8 F. Lindqwist, Analyst, 97,549 (1972).

9 H. W. Bay, K. F. Blurton, H. C. Lieb and H. G. Oswin, Int. Laboratory, Sept., 37 (1972).

10 F. Bruner and P. Ciccioli, Special Environmental Report, p 324. WMO: Geneva (1973).

11 F. Bruner, P. Ciccioli and F. Di Nardo, J. Chromatogr., 89661 (1974).

12 A. Liberti, Pure Appl. Chem. 24, 631 (1970).

13 M. Mascini and A. Liberti, Gazz. Chim. Ital. 103, 989 (1973).

14 A. R. Barringer, Enoironmental Poll. Instrumentation, p 49, Instrument Society of America: Pittsburgh (1969).

15 P. L. Hanst and J. A. Morreal, Air Pollut. Control Ass. 18, 754 (1968).

16 T. Kobayasi and H. Inaba, Proc. IEEE 58, 1568 (1970). 